\title{
A Novel Model of Chronic Kidney Disease in Rats: Dietary Adenine in Combination with Unilateral Nephrectomy
}

\author{
Cristina Muñoz Abellán ${ }^{\mathrm{a}-\mathrm{c}}$ Sandra Mangold-Gehring ${ }^{\mathrm{b}}$ Sina Micus ${ }^{\mathrm{c}}$ \\ Gerald Beddies $^{\mathrm{b}}$ Andreas Moritz ${ }^{\mathrm{a}}$ Elke Hartmann ${ }^{\mathrm{d}}$ Waldemar Lehmann ${ }^{\mathrm{c}}$ \\ Frank Eitner ${ }^{c}$ \\ ${ }^{a}$ Department of Veterinary Clinical Sciences, Clinical Pathology, and Clinical Pathophysiology, Justus Liebig

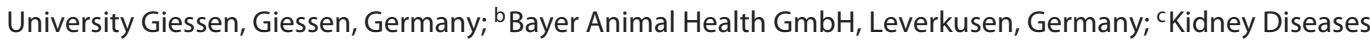

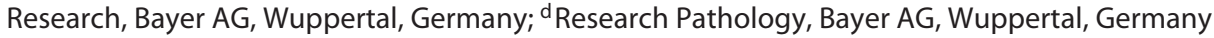

\section{Keywords}

Adenine $\cdot$ Chronic kidney disease model $\cdot$ Glomerular

filtration rate $\cdot$ Rat $\cdot$ Unilateral nephrectomy

\section{Abstract}

Background: Adenine at $0.75 \%$ in the diet (AD) triggers renal impairment in rats. This model of kidney disease is largely reversible when $A D$ feeding is stopped. Testing of novel drugs parallel to $A D$ administration may result in unwanted interference. Objectives: We hypothesized that combining $A D$ with unilateral nephrectomy $(\mathrm{UNx})$ would result in progressive chronic kidney disease (CKD) even after cessation of AD. Methods: In an explorative study, 16 rats with UNx (AD$1 \mathrm{~K}$ rats) and 10 sham-operated rats (AD-2K rats) received ADsupplemented feed for 3 weeks, followed by 4 weeks of standard chow. Ten sham-operated rats receiving only standard chow served as controls. Laboratory parameters in blood and urine were frequently assessed during and after cessation of AD feeding. Comprehensive pathological examinations were performed in all rats at the end of the experiment. Results: Rats with UNx were more affected by impaired glomerular filtration rate, anemia, hyperphosphatemia, and hy- pocalcemia. After cessation of AD feeding, recovery was poorest in AD-1K rats, paralleled by increased proteinuria indicative of progressive CKD. Scores in histopathological damage of the kidneys indicative of CKD were seen in both AD-fed groups, with key parameters being more affected in $A D-1 \mathrm{~K}$ rats. Histopathological changes in the heart were most prominent in $A D-1 \mathrm{~K}$ rats. Conclusions: Combining $A D$ feeding with UNx provides a time window after cessation of AD feeding for the testing of drugs without interference. Our findings in rats may have implications for research in other target animal species as well.

(c) 2019 S. Karger AG, Basel

\section{Introduction}

Rodent models of chronic kidney disease (CKD) are used to study the pathogenesis and pathophysiology of CKD and to develop therapeutic strategies.

C. Muñoz Abellán and S. Mangold-Gehring contributed equally to this work.
๑ 2019 S. Karger AG, Basel

E-Mail karger@karger.com

www.karger.com/kdd
Sandra Mangold-Gehring

Bayer Animal Health $\mathrm{GmbH}$

Alfred-Nobel-Strasse 50

DE-51381 Leverkusen (Germany)

E-Mail sandra.mangold@bayer.com 
Fig. 1. General study design to compare two CKD rodent models. Two weeks after surgery, groups $\mathrm{AD}-2 \mathrm{~K}$ and $\mathrm{AD}-1 \mathrm{~K}$ were fed an AD diet over 3 weeks. The control group was sham-operated and fed a standard rodent chow. Parameters to monitor disease progression were frequently assessed throughout the study. $\mathrm{AD}$, adenine at $0.75 \%$ in the diet; $\mathrm{AD}-1 \mathrm{~K}$ rats, rats with unilateral nephrectomy and $\mathrm{AD} ; \mathrm{AD}-2 \mathrm{~K}$ rats, sham-operated rats with $\mathrm{AD}$; $\mathrm{CKD}$, chronic kidney disease; UNx, unilateral nephrectomy.

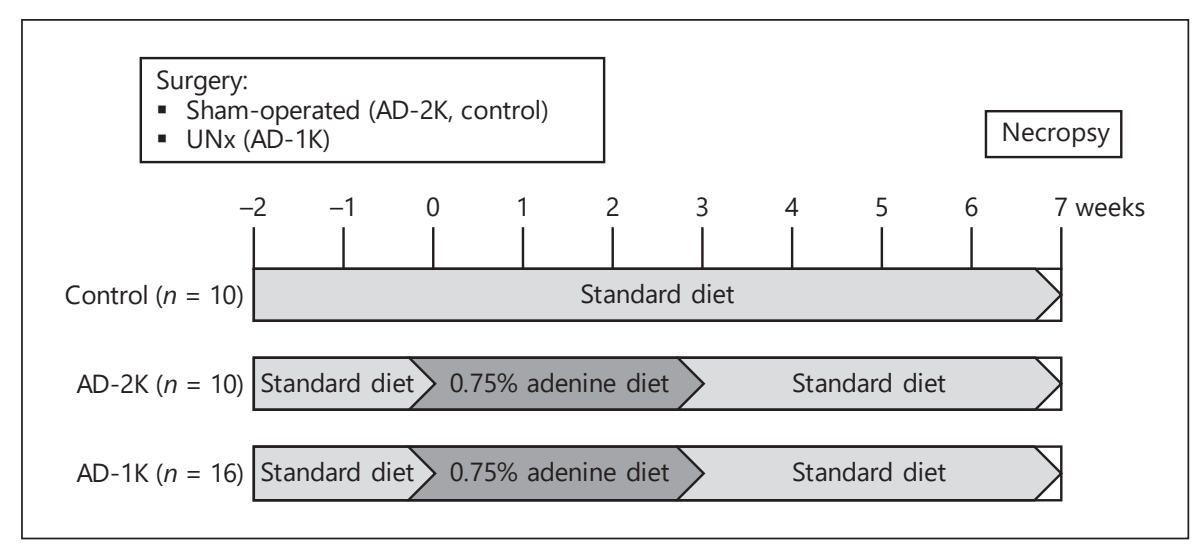

Orally administered adenine is metabolized to 2,8-dihydroxyadenine, which precipitates and crystallizes in proximal tubular epithelia, leading to an accumulation of crystals which causes degeneration of tubules. In rats, the induced renal impairment is characterized by uremia, hyperphosphatemia (related to secondary hyperparathyroidism), and renal anemia, depending on the duration of adenine exposure [1-3].

The severity of the adenine-induced kidney damage is correlated with the dose and the duration of the exposure [4]. Upon removal of adenine at $0.75 \%$ in the diet (AD) after 2 weeks of exposure, some of the effects are reversed and animals partly recover [4]. Longer exposure of rats to $\mathrm{AD}$ results in severe, irreversible kidney damage with high mortality, which makes this study protocol unsuitable as a model for testing novel therapeutic agents [4-6]. Some researchers tried to circumvent the limited longerterm tolerability of $\mathrm{AD}$ by exposing the rats to lower adenine concentrations $(0.25 \%)$ for up to 16 weeks $[7,8]$. However, therapeutic agents were administered in parallel to the adenine, which leaves open the possibility that these drugs might have interfered directly with the adenine toxicity (via uptake and/or metabolism).

A novel model of progressive $\mathrm{CKD}$, maintaining the state of progression after the end of adenine intake with limited or no recovery after adenine cessation, would allow testing of drugs after the cessation of adenine administration, thus avoiding any potential drug interference with the disease trigger.

In this explorative study, we tested the hypothesis that the preemptive removal of one kidney would aggravate the adenine-induced renal damage, resulting in a slower and less complete recovery after adenine cessation. Several studies with adenine diets in rodents have been published in the literature but, to our knowledge, adenine has never been combined with unilateral nephrectomy (UNx).

\section{Animals and Methods}

\section{Study Design}

The animals in this controlled, parallel-design study were randomly allocated to three study groups: (a) control group ( $n=10$; sham-operated rats, standard chow); (b) AD-2K group ( $n=10$; sham-operated rats, diet supplemented with $\mathrm{AD}$ ); (c) $\mathrm{AD}-1 \mathrm{~K}$ group ( $n=16$; UNx rats, diet supplemented with AD). Specific treatments started 2 weeks after surgery (day 0 ). Control rats received standard chow throughout the study. AD- $2 \mathrm{~K}$ and $\mathrm{AD}-1 \mathrm{~K}$ rats received $\mathrm{AD}$ for a total of 3 weeks from day 0 until day 20. From day 21 until the end of study on day 50, all rats received a standard diet. An overview is given in Figure 1.

\section{Animals}

At the age of 6-7 weeks, healthy male Sprague-Dawley rats Crl:CD(SD) - with a body weight range of 150-175 g at study start were obtained from Charles River, Sulzfeld, Germany and acclimatized for at least 1 week to the study facility. The rats were housed in accordance with Directive 2010/63/EU in polysulfone cages with wood granulate and equipped with environmental enrichment material. Animals were maintained under standard environmental conditions $\left(22 \pm 3{ }^{\circ} \mathrm{C}, 12 / 12 \mathrm{~h}\right.$ light and dark cycle, and approximately $55 \%$ humidity).

The animals had free access to water and a commercial standard chow (10-mm pellets, ssniff $\left.{ }^{\circledR} \mathrm{R} / \mathrm{M}-\mathrm{H}, \mathrm{V} 1534-0\right)$ containing among others the constituents $0.70 \%$ phosphorus, $1.00 \%$ calcium, $19.0 \%$ crude protein, $3.3 \%$ crude fat, $36.5 \%$ starch, and $4.7 \%$ sugar, supplemented with vitamins and trace elements. The AD diet was obtained from the same supplier (ssniff Spezialdiäten $\mathrm{GmbH}$, Soest, Germany) and contained $0.95 \%$ phosphorus, $0.92 \%$ calcium, $17.6 \%$ crude protein, $5.1 \%$ crude fat, $34.2 \%$ starch, and $11.3 \%$ sugar, supplemented with vitamins and trace elements. The higher content of fat and sugar in the adenine diet compared to the standard chow was intended to increase its palatability. The composition of the two diets was considered acceptable for the objectives of this study.

\section{Surgical Interventions}

A total of 36 rats aged 7-8 weeks were operated using standard sterile surgery and anesthesia methods. Sixteen rats received left UNx: after laparotomy the perirenal capsule was incised and cautiously detached without injuring the adrenals. The renal vessels 
Table 1. Analyzed parameters and time points

\begin{tabular}{lll}
\hline & Study days $^{1}$ & Parameters \\
\hline $\begin{array}{l}\text { Body } \\
\text { weight }\end{array}$ & $\begin{array}{l}1,2,4,5,11-14, \\
16,17,19,26, \\
\\
33,36,38,43\end{array}$ \\
\hline $\begin{array}{l}\text { Blood } \\
\text { chemistry }\end{array}$ & $-6,16,24,30$, & $\begin{array}{l}\text { creatinine, urea nitrogen, } \\
\text { phosphorus, calcium, sodium, } \\
\text { potassium, AST, ALT, AP, CK, } \\
\end{array}$ \\
& & LDH, GLDH, Fe \\
\hline Hematology & $-6,12,26,39$ & $\begin{array}{l}\text { hematocrit, erythrocytes, } \\
\text { hemoglobin, reticulocytes, } \\
\text { leukocytes, thrombocytes, MCH, } \\
\end{array}$ \\
& $-6,16,30,37$, & $\begin{array}{l}\text { MCHC, MCV } \\
\text { protein, creatinine, phosphorus, } \\
\text { calcium, sodium, potassium, } \\
\text { volume, osmolality }\end{array}$ \\
\hline Urine & 44 & GFR \\
\hline GFR & $-8,18,46$ & $\begin{array}{l}\text { gross pathology and } \\
\text { histopathology }\end{array}$ \\
\hline Necropsy & 49,50 &
\end{tabular}

Parameters were assessed before, during, and after AD feeding (days $0-20)$ in control $(n=10), \mathrm{AD}-2 \mathrm{~K}(n=10)$, and $\mathrm{AD}-1 \mathrm{~K}(n=$ 16) rats; values of days -8 and -6 were used as baseline. $A D$, adenine at $0.75 \%$ in the diet; $\mathrm{AD}-1 \mathrm{~K}$ rats, rats with unilateral nephrectomy, adenine at $0.75 \%$ in the diet; $\mathrm{AD}-2 \mathrm{~K}$ rats, sham-operated rats, adenine at $0.75 \%$ in the diet; GFR, glomerular filtration rate. ${ }^{1}$ Samples were collected on 1-2 consecutive days and collated.

were ligated for in toto removal of the kidney. Abdominal suture was done in two layers. All other rats underwent sham surgery to the abdomen; kidneys were not removed in these sham surgeries. Postoperative analgesics (carprofen or buprenorphine) were administered over 3 days. No antibiotics were required.

\section{Monitoring of Disease Progression}

The parameters frequently assessed throughout the study included body weight, blood and urine chemistry, hematology, and glomerular filtration rate (GFR). An overview is given in Table 1 . Blood specimens were collected by tongue puncture under anesthesia and collected in heparin tubes for clinical chemistry and in EDTA tubes for hematology. Urine samples were collected by means of metabolic cages during a period of $15 \mathrm{~h}$. During this period, animals had no access to feed and unlimited access to water.

GFR was measured with an exogenous tracer and a transcutaneous detection method as previously reported $[9,10]$. Briefly, on the days prior to GFR measurement, an area of the animal's skin was depilated and a photodiode was fixed to the back using plasters. On the following day, fluorescein-isothiocyanate-labeled sinistrin (FITC-S) was administered by a single intravenous injection at $40 \mathrm{mg} / \mathrm{kg}$. The decay curve of fluorescence was recorded during a period of $2 \mathrm{~h}$ after intravenous administration for the calculation of GFR. Animals could move freely during the recording period.
Table 2. Glomerular filtration rate $(\mathrm{mL} / \mathrm{min})$

\begin{tabular}{lllll}
\hline & $n$ & Day 8 & Day 18 & Day 46 \\
\hline Control & 10 & $1.65 \pm 0.28$ & $1.65 \pm 0.39$ & $1.65 \pm 0.39$ \\
AD-2K & 10 & $1.40 \pm 0.16$ & $0.37 \pm 0.08^{\mathrm{a}}$ & $0.64 \pm 0.22^{\mathrm{a}}$ \\
AD-1K & 16 & $1.21 \pm 0.36$ & $0.23 \pm 0.06^{\mathrm{a}}$ & $0.31 \pm 0.12^{\mathrm{a}}$ \\
\hline
\end{tabular}

Values are presented as means \pm standard deviation. $\mathrm{AD}-1 \mathrm{~K}$ rats, rats with unilateral nephrectomy, adenine at $0.75 \%$ in the diet; $\mathrm{AD}-2 \mathrm{~K}$ rats, sham-operated rats, adenine at $0.75 \%$ in the diet. ${ }^{\mathrm{a}} \mathrm{Sig}$ nificant difference versus control $(p<0.05)$; day -8 was used as baseline. Glomerular filtration rate was measured transcutaneously using fluorescein-isothiocyanate-labeled sinistrin as a tracer.

Four weeks after cessation of the adenine diet, all rats were necropsied and organs were harvested for histopathological examinations using hematoxylin-eosin stain. The severity of histopathological findings in the affected organs (kidney, heart, aorta, and stomach) was assessed and scored semiquantitatively $(0=$ absent, $1=$ minimal, $2=$ slight, $3=$ moderate, $4=$ marked, $5=$ massive $)$ by a pathologist.

\section{Statistical Analysis}

Statistical analysis and generation of tables, subject data listings, and figures were performed using the SAS ${ }^{\circledR}$ software package version 9.4 under the Microsoft Windows ${ }^{\circledR} 7$ Professional operating system. Analyses were conducted in the complete set of all randomized study animals $(n=36)$. The experimental unit was the individual study animal. For each post-baseline study day, exploratory $p$ values for testing the effects of "treatment" and "covariate" as well as the between- (i.e., multiple comparisons between the three different treatment groups) and within- (i.e., comparison of the post-baseline value versus the baseline value within each treatment group and overall) treatment group effects were calculated by nonparametric Wilcoxon rank-sum test. For clinical chemistry, hematology, and urinary parameters study day -6 was the baseline time point. Day -8 was the baseline time point for GFR and day 1 was the baseline time point for body weight. All statistical tests and confidence intervals were interpreted descriptively at a nominal significance level of $5 \%$.

\section{Results}

\section{Kidney Function}

Plasma creatinine and plasma urea nitrogen measured throughout the study were used as indirect measures of GFR. AD feeding resulted in a significant rise in plasma creatinine and urea nitrogen in groups $A D-2 K$ and $\mathrm{AD}-1 \mathrm{~K}$ (Fig. 2). Plasma creatinine and urea nitrogen were significantly $(p<0.05)$ increased in both adeninetreated groups on all days of assessment compared to controls. GFR recovered after changing the diet back to a standard chow. UNx resulted in a more pronounced 


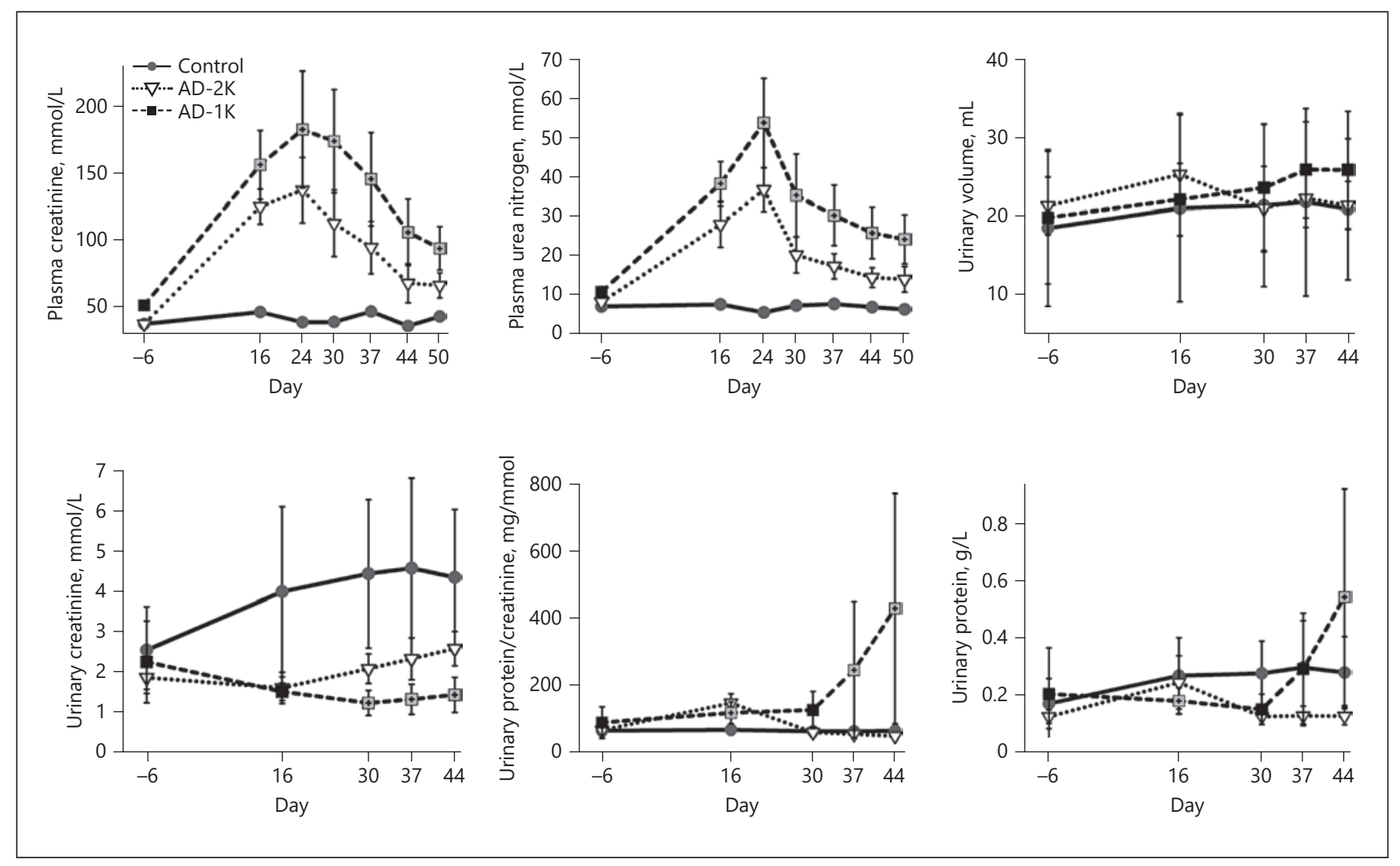

Fig. 2. Kidney function parameters longitudinally assessed in the rats. The graphic illustrates arithmetic mean values and standard deviations on each of the specified study days. The values of AD-1K rats are plotted as black or crossed grey squares. Crossed grey squares refer to a significant difference of AD-1K versus AD-2K rats $(p<$ 0.05 , change from baseline). $\mathrm{AD}-1 \mathrm{~K}$ rats, rats with unilateral nephrectomy, adenine at $0.75 \%$ in the diet; $\mathrm{AD}-2 \mathrm{~K}$ rats, sham-operated rats, adenine at $0.75 \%$ in the diet.

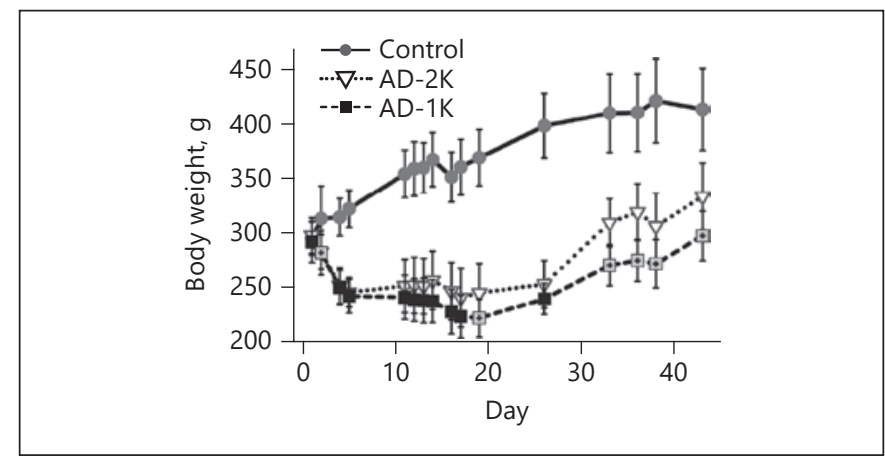

Fig. 3. Body weights longitudinally assessed in the rats. The graphic illustrates arithmetic mean values and standard deviations on each of the specified study days. $\mathrm{AD}-1 \mathrm{~K}$ values are plotted as black or crossed grey squares. Crossed grey squares refer to a significant difference of $\mathrm{AD}-1 \mathrm{~K}$ versus $\mathrm{AD}-2 \mathrm{~K}$ rats $(p<0.05$, change from baseline). $\mathrm{AD}-1 \mathrm{~K}$ rats, rats with unilateral nephrectomy, adenine at $0.75 \%$ in the diet; $\mathrm{AD}-2 \mathrm{~K}$ rats, sham-operated rats, adenine at $0.75 \%$ in the diet. peak injury and a slower recovery. Direct measurements of GFR using FITC-S confirmed these findings (Table 2). The GFR loss was most pronounced in the AD-1K group, which showed hardly any recovery during adenine washout.

$\mathrm{AD}$ feeding resulted in a mild increase of proteinuria (measured as the urinary protein-creatinine ratio) which was rapidly reversible in the $\mathrm{AD}-2 \mathrm{~K}$ group (Fig. 2). UNx (AD-1K group), however, impaired the proteinuria recovery and resulted in a prominent proteinuria increase after cessation of the AD feeding. There were no significant differences in urine volume between the three study groups (Fig. 2).

Urinary creatinine concentrations (Fig. 2) were significantly and comparably reduced during adenine treatment in both groups - $\mathrm{AD}-2 \mathrm{~K}(1.62 \mathrm{mmol} / \mathrm{L})$ and $\mathrm{AD}-1 \mathrm{~K}$ $(1.53 \mathrm{mmol} / \mathrm{L})$ compared to control rats on a regular diet $(4.00 \mathrm{mmol} / \mathrm{L})$. After cessation of the adenine diet, uri- 


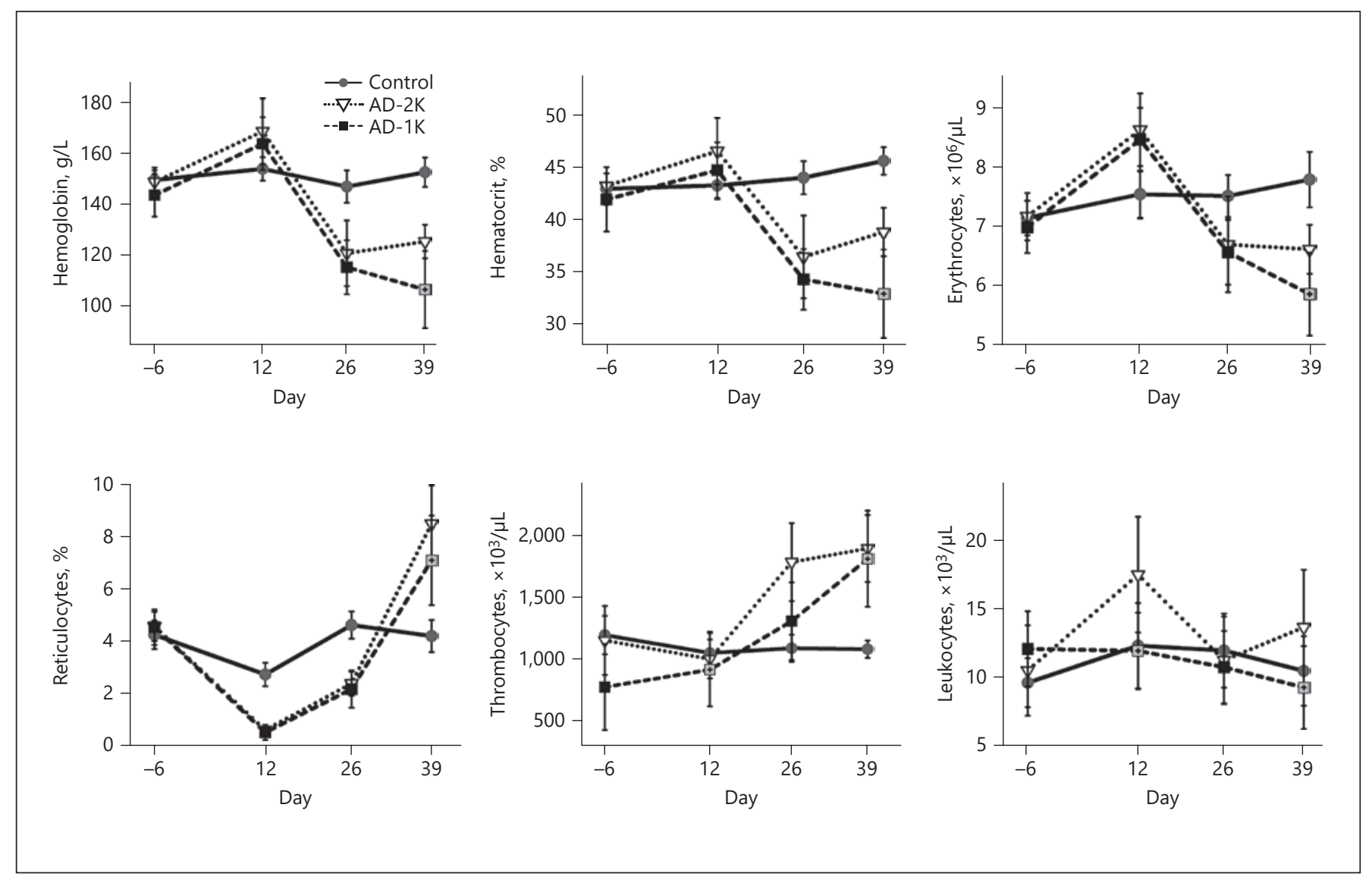

Fig. 4. Hematology parameters longitudinally assessed in the rats. The graphic illustrates arithmetic mean values and standard deviations on each of the specified study days. AD-1K values are plotted as black or crossed grey squares. Crossed grey squares refer to a significant difference of $\mathrm{AD}-1 \mathrm{~K}$ versus $\mathrm{AD}-2 \mathrm{~K}$ rats $(p<0.05$, change from baseline). $\mathrm{AD}-1 \mathrm{~K}$ rats, rats with unilateral nephrectomy, adenine at $0.75 \%$ in the diet; $\mathrm{AD}-2 \mathrm{~K}$ rats, sham-operated rats, adenine at $0.75 \%$ in the diet.

nary creatinine concentrations normalized only in the $\mathrm{AD}-2 \mathrm{~K}$ group $(2.6 \mathrm{mmol} / \mathrm{L})$, while in the $\mathrm{AD}-1 \mathrm{~K}$ group the reduced level persisted $(1.45 \mathrm{mmol} / \mathrm{L})$.

\section{Body Weight}

The baseline body weights of the rats in the three study groups were comparable (Fig. 3). AD feeding resulted in a decrease in body weight. $\mathrm{UNx}$ (AD-1K group) had no immediate impact on the severity of adenineassociated decline in body weight. Until day 17 both adenine-fed groups had comparable body weights. Upon cessation of adenine on day 20, body weights increased continuously in groups $\mathrm{AD}-2 \mathrm{~K}$ and $\mathrm{AD}-1 \mathrm{~K}$ until study end. However, the body weight recovery in the AD-2K group was better than that in $\mathrm{AD}-1 \mathrm{~K}$ rats, resulting in significant group differences after day 19 until study end.

Novel Rat Adenine Unilateral

Nephrectomy CKD Model

\section{CKD-Associated Secondary Complications}

Adenine treatment-associated renal impairment resulted in profound renal anemia. While shortly after the cessation of the adenine diet the $\mathrm{AD}-2 \mathrm{~K}$ and $\mathrm{AD}-1 \mathrm{~K}$ groups did not differ significantly with respect to the severity of their anemia, $\mathrm{AD}-1 \mathrm{~K}$ rats progressed further towards more advanced anemia, while $\mathrm{AD}-2 \mathrm{~K}$ rats started to recover. On day 39 hemoglobin, hematocrit, erythrocyte, and reticulocyte counts were significantly lower in $\mathrm{AD}-1 \mathrm{~K}$ than in $\mathrm{AD}-2 \mathrm{~K}$ rats. With respect to white cell counts, $\mathrm{AD}-2 \mathrm{~K}$ rats showed a mild increase and $\mathrm{AD}-1 \mathrm{~K}$ rats a mild decrease in leukocytes on day 39 . Thrombocyte count was equally elevated in both the $\mathrm{AD}-2 \mathrm{~K}$ and $\mathrm{AD}-1 \mathrm{~K}$ groups following cessation of the adenine diet (Fig. 4).

The adenine diet resulted in significant changes in plasma phosphate and plasma calcium levels similar to 
Fig. 5. Plasma and urinary phosphate and calcium levels longitudinally assessed in the rats. The graphic illustrates arithmetic mean values and standard deviations on each of the specified study days. AD-1K values are plotted as black or crossed grey squares. Crossed grey squares refer to a significant difference of $\mathrm{AD}-1 \mathrm{~K}$ versus $\mathrm{AD}$ $2 \mathrm{~K}$ rats $(p<0.05$, change from baseline). $\mathrm{AD}-1 \mathrm{~K}$ rats, rats with unilateral nephrectomy, adenine at $0.75 \%$ in the diet; AD- $2 \mathrm{~K}$ rats, sham-operated rats, adenine at $0.75 \%$ in the diet.
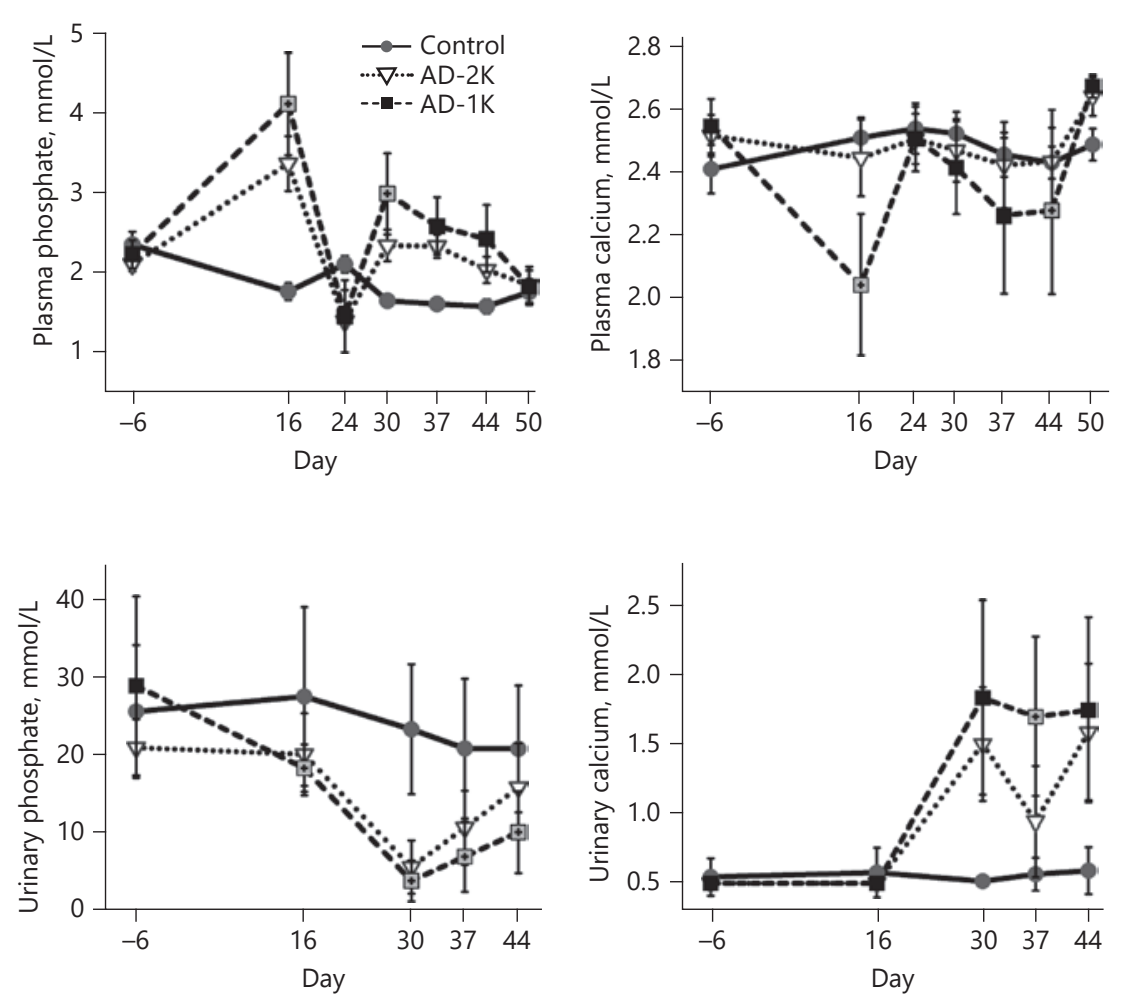

what is known for human CKD-associated mineral bone disorders. There was a marked rise in plasma phosphate in both adenine-treated groups that was more distinct in the $\mathrm{AD}-1 \mathrm{~K}$ group. The $\mathrm{AD}-1 \mathrm{~K}$ group showed slower recovery from hyperphosphatemia after adenine cessation compared with the $\mathrm{AD}-2 \mathrm{~K}$ group. The hyperphosphatemia was accompanied by hypocalcemia, hypophosphaturia, and hypercalciuria, which again was more pronounced in the $\mathrm{AD}-1 \mathrm{~K}$ group (Fig. 5).

\section{Histopathology}

The kidneys of all adenine-treated rats showed (partly cystic) dilatation, degeneration, and atrophy of tubules, interstitial fibrosis, presence of giant cells with abundant deposition of adenine crystals, and mononuclear cell infiltration. Such features were completely absent in the kidneys of control rats (Fig. $6 \mathrm{a}-\mathrm{c}$ ). Glomeruli of the kidneys were intact in all groups. Table 3 presents histopathological findings numerically with semiquantitative severity scores. Severity scores of tubular injury and the incidence of mineralization and pelvic dilatation were higher among $\mathrm{AD}-1 \mathrm{~K}$ rats.
The heart, aorta, and stomach were microscopically assessed to see whether the adenine diet had affected these organs. No findings were seen in any of the control rats. Minimal or slight focal degeneration of cardiac tissue was seen in several rats of both adenine-treated groups, with a higher incidence among $\mathrm{AD}-1 \mathrm{~K}$ rats. Only rats of the $\mathrm{AD}-1 \mathrm{~K}$ group had developed vasculopathy of cardiac tissue (Fig. 6d-f). No mineralization of cardiac, aortic, or stomach tissue was seen in any of the groups.

\section{Discussion}

There is still a need for novel robust and reliable animal models for the testing of drugs targeting CKD. As most rodent models for CKD have studied male animals only [11], we focused on this sex, expecting more homogenous and pronounced effects. Frequently used rat CKD models are induced by ureteral obstruction, ischemia/reperfusion injury, or subtotal 5/6 nephrectomy. In essence, all models come with certain limitations. Briefly, the unilateral ureter obstruction model which, is used to exam- 

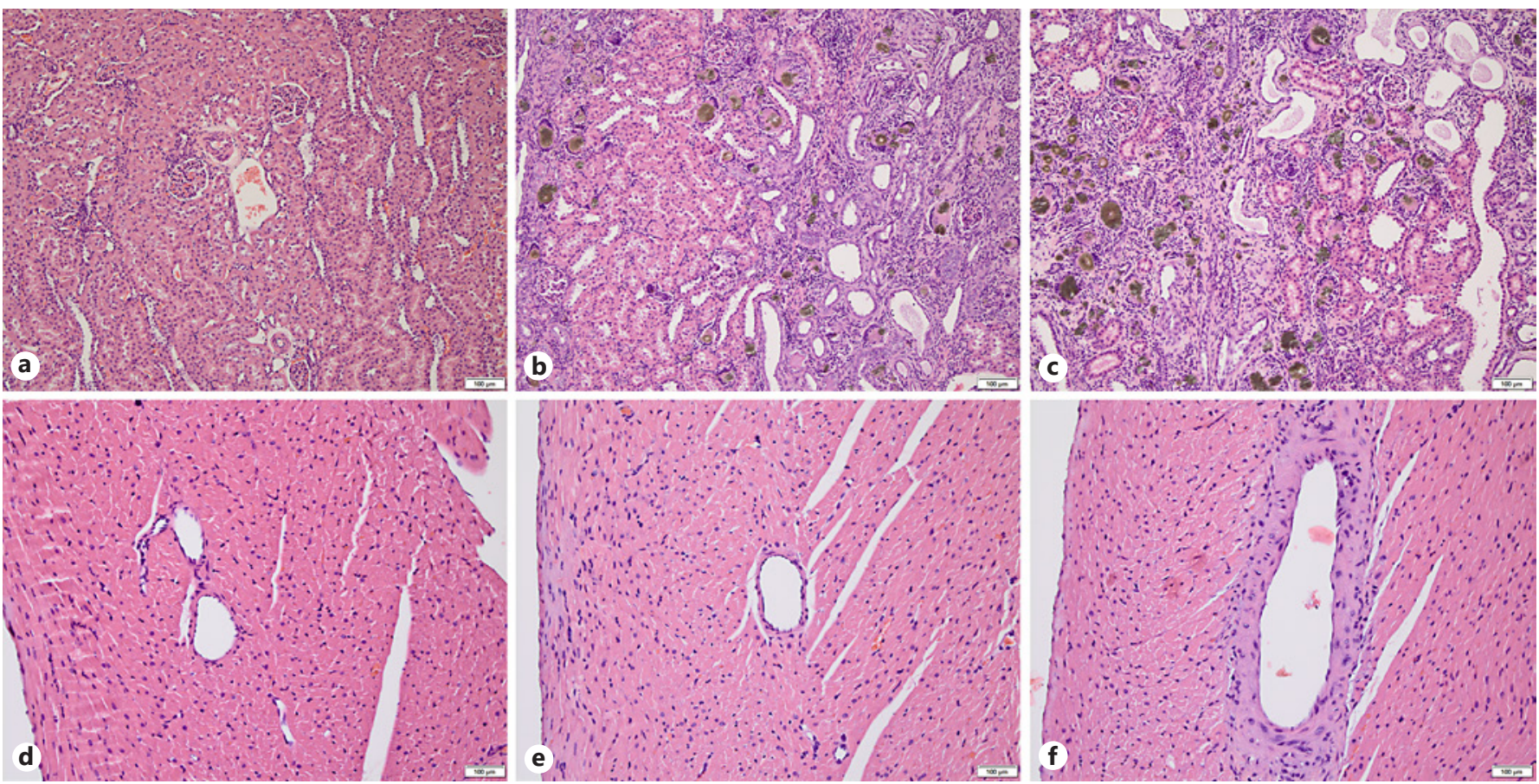

Fig. 6. Histopathology. Hematoxylin-eosin stains of kidney (a-c) and right heart ventricle (d-f) of control (a, d), $\mathrm{AD}-2 \mathrm{~K}(\mathbf{b}, \mathbf{e})$ and $\mathrm{AD}-1 \mathrm{~K}(\mathbf{c}, \mathbf{f})$ rats. b, c Brownish adenine crystals with giant cell formation, cystic tubular dilatation, interstitial fibrosis, mononuclear cell infiltrate, and tubular atrophy/degeneration. The semiquantitative degree of tubular damage was marked in $\mathrm{AD}-1 \mathrm{~K}$ rats (c), while tubular damage in $\mathrm{AD}-2 \mathrm{~K}$ rats (b) was only moderate, with intact eosinophilic areas (left half of the picture). Vasculopathy of slight degree with thickening of the ventricular artery wall was only seen in $\mathrm{AD}-1 \mathrm{~K}$ rats (f). Scale bars, $100 \mu \mathrm{m}$. AD- $1 \mathrm{~K}$ rats, rats with unilateral nephrectomy, adenine at $0.75 \%$ in the diet; $\mathrm{AD}$ $2 \mathrm{~K}$ rats, sham-operated rats, adenine at $0.75 \%$ in the diet.

Table 3. Histopathological findings

\begin{tabular}{|c|c|c|c|c|c|c|c|}
\hline & & \multicolumn{3}{|c|}{$\begin{array}{l}\text { Percentage of rats with pathological } \\
\text { findings }\end{array}$} & \multicolumn{3}{|c|}{$\begin{array}{l}\text { Semiquantitative mean } \\
\text { severity score }\end{array}$} \\
\hline & & control & $\mathrm{AD}-2 \mathrm{~K}$ & $\mathrm{AD}-1 \mathrm{~K}$ & control & $\mathrm{AD}-2 \mathrm{~K}$ & $\mathrm{AD}-1 \mathrm{~K}$ \\
\hline \multirow{8}{*}{ Kidney } & tubular dilatation/cysts & 0 & 100 & 100 & 0 & 2.7 & 3.9 \\
\hline & tubular degeneration/atrophy & 0 & 100 & 100 & 0 & 3.6 & 4.0 \\
\hline & pelvic dilatation & 0 & 0 & 25 & 0 & 0 & 2.5 \\
\hline & mineralization & 0 & 10 & 25 & 0 & 2.0 & 1.5 \\
\hline & adenine crystals & 0 & 100 & 100 & 0 & 4.0 & 4.0 \\
\hline & giant cells & 0 & 100 & 100 & 0 & 3.1 & 3.0 \\
\hline & interstitial fibrosis & 0 & 100 & 100 & 0 & 3.1 & 3.1 \\
\hline & mononuclear infiltration & 0 & 100 & 100 & 0 & 3.2 & 3.0 \\
\hline \multirow[t]{2}{*}{ Heart } & focal degeneration & 0 & 30 & 56.3 & 0 & 1.7 & 1.8 \\
\hline & vasculopathy & 0 & 0 & 43.8 & 0 & 0 & 1.4 \\
\hline \multirow{2}{*}{ Stomach } & inflammatory infiltration & 0 & 0 & 6.3 & 0 & 0 & 1.0 \\
\hline & erosion & 0 & 0 & 6.3 & 0 & 0 & 1.0 \\
\hline
\end{tabular}

Percentages and scores indicative for higher incidence/severity in $\mathrm{AD}-1 \mathrm{~K}$ rats are highlighted in bold. AD- $1 \mathrm{~K}$ rats, rats with unilateral nephrectomy, adenine at $0.75 \%$ in the diet; $\mathrm{AD}-2 \mathrm{~K}$ rats, sham-operated rats, adenine at $0.75 \%$ in the diet.

Novel Rat Adenine Unilateral

Nephrectomy CKD Model
Kidney Dis 2019;5:135-143

DOI: $10.1159 / 000495750$ 
ine mechanisms of tubulointerstitial fibrosis in vivo [12], does not allow monitoring of functional parameters, as the intact contralateral kidney ensures homeostasis of kidney parameters. Different models of ischemic acute renal failure and reperfusion are commonly used by clamping of renal arteries [13]. The consequences of ischemic acute renal failure and reperfusion are proportional to the period of ischemia and have to be determined for the individual rat strain and age. The functional effect remains highly variable, with even small differences in ischemia and reperfusion time significantly changing the characteristics of the model and therefore making comparative studies problematic. These models are mainly driven by acute inflammatory processes that are often reversible and only allow acute studies.

Subtotal nephrectomy, 5/6 nephrectomy, is probably the most established chronic method of modeling the progressive renal failure seen with loss of renal mass [13]. Rather than mimicking a renal disease per se, subtotal nephrectomy reproduces the consequences of an acute reduction in functional renal mass with acute hyperfiltration. The model is characterized by progressive proteinuria, disturbed tubular electrolyte transport, reduced GFR, and increased urinary volume. The predominant pathological abnormalities are glomerulosclerosis and tubulointerstitial fibrosis. The rate of progression to renal failure is very closely related to the amount of tissue excised. The model is technically challenging and variable, as insufficient mass reduction prevents the development of kidney insufficiency and reducing too much kidney tissue would lead to death. The variability of the model, however, still poses problems for interventionist experiments. Furthermore the characteristic vessel damages in kidney patients, such as calcification and stiffness, can only be shown after long duration or application of additional triggers like phosphate, calcium, and vitamin D in chow [14].

We were able to support our hypothesis that a combination of UNx and adenine diet results in a more pronounced kidney disease that is less likely to recover after adenine cessation.

The assessed indicators of GFR (plasma creatinine, plasma urea, and FITC-S measured GFR) demonstrated severe loss of excretory kidney function that particularly persisted in $\mathrm{AD}-1 \mathrm{~K}$ rats. The lack of a statistically significant difference between $\mathrm{AD}-1 \mathrm{~K}$ and $\mathrm{AD}-2 \mathrm{~K}$ on day 46 can be explained by the low baseline value of the $\mathrm{AD}-1 \mathrm{~K}$ group. The directly measured GFR unmasked the true lack of GFR recovery, underlining the importance of directly measuring GFR in preclinical models in general.
Loss of body weight is a major issue in the adenine CKD model, and therefore restriction of the adenine feeding period is required. Decreases in body weight are known to occur upon pair feeding [6] or oral gavage administration [15] of adenine. In this study, UNx had no immediate impact on weight gain since the body weights of the $\mathrm{AD}-1 \mathrm{~K}$ and $\mathrm{AD}-2 \mathrm{~K}$ animals were similar during the first 17 days of $\mathrm{AD}$ feeding. After adenine cessation, the lowest gain in body weight was seen in $\mathrm{AD}-1 \mathrm{~K}$ animals.

In previous studies, where rats were given an $\mathrm{AD}$ diet for 3 weeks followed by a normal diet, anemia associated with kidney disease developed at week 4 and persisted to week 8, with hemoglobin levels at around $90 \mathrm{~g} / \mathrm{L}$ and hematocrit at $25 \%$ [3]. The decrease in hemoglobin was due to a decrease in red blood cell production, as shown by a drastic reduction in reticulocyte count at week 1 . These published data are in agreement with the results shown in our study: all animals fed with adenine showed a decrease in hematocrit, erythrocytes, and hemoglobin at week 4 that persisted until the end of the study, accompanied by a drastic reduction in reticulocytes during adenine feeding lasting until week 4 . Remarkably, the resulting renal anemia was more aggravated in $\mathrm{AD}-1 \mathrm{~K}$ animals.

The adenine rat model is also frequently used to study aspects of CKD-associated mineral bone disease, particularly hyperphosphatemia and secondary hyperparathyroidism. Our data indicate that the preemptive UNx offers a window following adenine cessation with persistent hyperphosphatemia and hypocalcemia, which could be used for drug testing whilst avoiding a simultaneous administration of adenine.

The histopathological findings in the kidneys were in good congruence to those described in the literature [5]; precipitates and crystals occurred in the apical epithelial region of proximal tubules associated with tubular degradation, atrophy, and dilatation. The observed focal degeneration of cardiac tissues and cardiac vasculopathy might be an indicator of increased cardiovascular morbidity in the $\mathrm{AD}-1 \mathrm{~K}$ rats that merits further studies directed at reducing CKD-associated cardiovascular mortality.

To our knowledge, the present study used for the first time dietary adenine intake combined with UNx. Our results indicate that the combination with UNx will allow restriction of the adenine feeding period, while the animals are still exhibiting characteristics of a progressive state of CKD. UNx offers a window following adenine cessation which could allow testing of drugs designed to intervene with CKD progression or secondary CKD complications with better accuracy and over a longer period of time without concurrent interaction of a trigger. 


\section{Acknowledgments}

Dr. C. Muñoz Abellán died in an airplane crash on March 24, 2015. She was employed by TransMIT GmbH and worked as a collaborative postdoc researcher for the Department of Veterinary Clinical Sciences at the Justus Liebig University Giessen as well as the Animal Health Division and the Kidney Diseases Research Division at Bayer AG. This paper summarizes the setup and findings of the key study that she was responsible for. We would like to dedicate this paper to her memory. We thank Cemile Jakupoglu, Cyton AH Biosciences $\mathrm{GmbH}$, who helped compiling the data and drafting the manuscript.

\section{Statement of Ethics}

The study procedures adhered to the current national legislation (German protection of animals act [2006/05/18], last amended by article 4 paragraph 87 [BGBl. I S. 1666] on July 18, 2016, and the EU directives 63/2010 [on the protection of animals used for scientific purposes]). All animal experiments were in accordance with the ethical standards of the institution and approved by the local and governmental review boards. No informed consent was required for this study with laboratory rodents. All institutional and national guidelines for the care and use of laboratory animals were followed.

\section{Disclosure Statement}

The studies reported here were funded by Bayer AG and Bayer Animal Health GmbH, Germany. S. Mangold-Gehring and G. Beddies are full-time employees of Bayer Animal Health GmbH. S. Micus, E. Hartmann, W. Lehmann, and F. Eitner are full-time employees of Bayer AG, Germany.

\section{Author Contributions}

Study design: C. Muñoz Abellán, S. Micus, G. Beddies, A. Moritz, F. Eitner. Study execution: C. Muñoz Abellán, S. Micus, W. Lehmann, E. Hartmann. Data analysis: C. Muñoz Abellán, S. Micus, G. Beddies, S. Mangold-Gehring, A. Moritz, E. Hartmann, F. Eitner. Manuscript preparation: S. Mangold-Gehring, S. Micus, G. Beddies, A. Moritz, E. Hartmann, F. Eitner.

\section{References}

1 Ali BH, Al-Salam S, Al Husseni I, Kayed RR, Al-Masroori N, Al-Harthi T, et al. Effects of Gum Arabic in rats with adenine-induced chronic renal failure. Exp Biol Med (Maywood). 2010 Mar;235(3):373-82.

2 Santana AC, Degaspari S, Catanozi S, Dellê H, de Sá Lima L, Silva C, et al. Thalidomide suppresses inflammation in adenine-induced CKD with uraemia in mice. Nephrol Dial Transplant. 2013 May;28(5):1140-9.

3 Sun CC, Vaja V, Chen S, Theurl I, Stepanek A, Brown DE, et al. A hepcidin lowering agent mobilizes iron for incorporation into red blood cells in an adenine-induced kidney disease model of anemia in rats. Nephrol Dial Transplant. 2013 Jul;28(7):1733-43.

4 Okada H, Kaneko Y, Yawata T, Uyama H, Ozono S, Motomiya Y, et al. Reversibility of adenine-induced renal failure in rats. Clin Exp Nephrol. 1999;3(2):82-8.

5 Claramunt D, Gil-Peña H, Fuente R, Hernández-Frías O, Santos F. Animal models of pediatric chronic kidney disease. Is adenine intake an appropriate model? Nefrologia. 2015 Nov-Dec;35(6):517-22.
6 Ferrari GO, Ferreira JC, Cavallari RT, Neves KR, dos Reis LM, Dominguez WV, et al. Mineral bone disorder in chronic kidney disease: head-to-head comparison of the 5/6 nephrectomy and adenine models. BMC Nephrol. 2014 May;15(1):69.

7 Diwan V, Gobe G, Brown L. Glibenclamide improves kidney and heart structure and function in the adenine-diet model of chronic kidney disease. Pharmacol Res. 2014 Jan;79: 104-10.

8 Diwan V, Small D, Kauter K, Gobe GC, Brown L. Gender differences in adenine-induced chronic kidney disease and cardiovascular complications in rats. Am J Physiol Renal Physiol. 2014 Dec;307(11):F1169-78.

9 Schock-Kusch D, Sadick M, Henninger N, Kraenzlin B, Claus G, Kloetzer HM, et al. Transcutaneous measurement of glomerular filtration rate using FITC-sinistrin in rats. Nephrol Dial Transplant. 2009 Oct;24(10): 2997-3001.
10 Schock-Kusch D, Xie Q, Shulhevich Y, Hesser J, Stsepankou D, Sadick M, et al. Transcutaneous assessment of renal function in conscious rats with a device for measuring FITC-sinistrin disappearance curves. Kidney Int. 2011 Jun;79(11):1254-8.

11 Diwan V, Brown L, Gobe GC. Adenine-induced chronic kidney disease in rats. $\mathrm{Ne}$ phrology (Carlton). 2018 Jan;23(1):5-11.

12 Chevalier RL, Forbes MS, Thornhill BA. Ureteral obstruction as a model of renal interstitial fibrosis and obstructive nephropathy. Kidney Int. 2009 Jun;75(11):1145-52.

13 Hewitson TD, Ono T, Becker GJ. Small animal models of kidney disease: a review. Methods Mol Biol. 2009;466:41-57.

14 Lopez I, Mendoza FJ, Aguilera-Tejero E, Perez J, Guerrero F, Martin D, et al. The effect of calcitriol, paricalcitol, and a calcimimetic on extraosseous calcifications in uremic rats. Kidney Int. 2008 Feb;73(3):300-7.

15 Fong D, Ullah MM, Lal JG, Abdelkader A, Ow CP, Hilliard LM, et al. Renal cellular hypoxia in adenine-induced chronic kidney disease. Clin Exp Pharmacol Physiol. 2016 Oct; 43(10): 896-905.
Novel Rat Adenine Unilateral

Nephrectomy CKD Model 